\title{
EDITORIAL
}

\section{EJHS in Constant Progress}

\author{
Tekle Ferede, Managing Editor
}

\section{DOI: http://dx.doi.org/10.4314/ejhs.v26i2.1}

Hosted by Jimma University, the Ethiopian Journal of Health Sciences (EJHS) has been publishing peerreviewed articles on a range of topics pertaining to public health and medicine. EJHS has always aspired to: 1) provide current scientific and technological information on health and related fields for informed planning and decision making, and 2) contribute to the scientific knowledge and practices in medicine, public health and related fields by providing a formal means for researchers to share their scientific research works, observations and experiences.

The first issue of EJHS emerged in July 1990 under the former name of the journal, "Bulletin of Jimma Institute of Health Sciences". Since then, EJHS made several strides to reach scientists, academicians, policy makers and other readers or users. In its journey from then onwards, EJHS underwent several quantitative and qualitative transformations. From its commencement to 1995, it appeared biannually with its initial name mentioned above. In those years, EJHS was characterized by changes in form, cover colour, contents and manuscript sources. Its form changed from A-5 to A3 and its cover colour from yellow to white and then to blue. Its contents also varied significantly in quantity and quality. Yet, almost all the manuscript contributors during the stated period were from the then Jimma Institute of Health Sciences.

The next stage covers the years of 1996-2007 when EJHS suffered from sluggish development. The one noteworthy change then was the change in name from "Bulletin of Jimma Institute of Health Sciences" to "Ethiopian Journal of Health Sciences". This coincided with the emergence of a full-fledged Jimma University. However, the biannual appearance, the A-5 size format and the blue colour were maintained. Besides, the quantity, the diversity and the quality of the articles published in each issue did not exhibit noticeable changes. Luckily, few authors from other parts of Ethiopia began contributing manuscripts although international contributions were yet to happen.

EJHS registered a commendable development from 2008 to 2013. The first two fundamental changes in this period were the change in format from A-5 to A-3 and the growth of the journal from biannual to triannual publication. The articles published in successive issues also improved substantially in quantity and quality. In 2008, EJHS joined African Journals Partnership Project (AJPP), which is funded by the US National Institute of Health/National Library of Medicine (NLM). With AJPP support, the Editor-in-Chief of EJHS became member of the Council of Science Editors. AJPP also helped EJHS partner with Annals of Internal Medicine published by American College of Physicians. In 2009, EJHS launched its own website where all publications are uploaded for open access. In 2010, it began using ScholarOne-Manuscript Central software for manuscript management. This resulted in the termination of the submission of manuscripts in print copies. In the same year, EJHS joined Committee for Publication Ethics (COPE), while it was indexed on PubMed Central, African Journal Online (AJOL) and EBSCO in 2011. In the end of 2012, it was indexed on MEDLINE. Although EJHS did not win the competition to become member of International Committee of Medical Journal Editors (ICMJE) in 2011, it succeeded in 2013 as a result of which the Editor-in-Chief joined this international group. The international involvement helped to considerably increase the visibility of EJHS. The remarkable growth in the number of readers and the massive submission of manuscripts from all parts of the world witnessed this phenomenon. This in turn demanded an increase in the frequency of publications.

In response to this situation, EJHS evolved into a quarterly publication during its $24^{\text {th }}$ anniversary in 2014. The continued increase in manuscript inflow still necessitated upgrading EJHS into a journal which publishes articles every two months. This progress is heralded with the publication of Volume 26, No. 2 (March 2016). This issue contains nine original articles, two reviews and two case reports which readers are invited to read and utilize. 